\title{
An Estimation of the Consumers Expenditure on the Consumption of American Foods
}

\author{
Pooja S. Bhat ${ }^{1 *}$, T.N. Venkata Reddy ${ }^{2}$ and P.K. Mandanna ${ }^{2}$ \\ ${ }^{I}$ Department of Agricultural and Rural Management, Tamil Nadu Agricultural University, \\ Coimbatore - 641003, Tamil Nadu, India \\ ${ }^{2}$ Department of Agricultural Marketing, Co-operation and Business Management, University \\ of Agricultural Sciences, GKVK, Bengaluru - 560 065, Karnataka, India \\ *Corresponding author
}

\section{A B S T R A C T}

\begin{tabular}{|l|}
\hline Ke y w o r d s \\
American foods, \\
Appetising, \\
Expenditure, Limited \\
Service Restaurants, \\
Satiety
\end{tabular}

American Food Restaurants (AFR) are uniquely designed restaurants accounting for a central and significant part of the Indian Food Service Industry. This study aims to draw attention towards lesser known aspects such as consumer's mode of purchase and relevance of American foods and their monthly expenditure and per visit expenditure on American foods, for which data was collected from 90 consumers of American style foods and seven American Food Restaurants (AFR's) were interviewed using a structured and pre-tested schedule in Bengaluru City and the collected data was analyzed using percentage analysis. Results proved that nearly three fourths of the consumers purchased American foods at the restaurant itself. The consumers who spent Rs. 2500-3000 on American foods per month constituted 25.56 per cent while a little more than two thirds of the consumers spent Rs. 100-500 on eating American foods (per visit).About 37.77 per cent of the consumers opined that they consumed American foods to satisfy cravings. The study recommends AFR's to offer special dishes and change the specials regularly in order to satisfy adventurous diners who would like to try out new flavours as preferred by the consumers.

\section{Introduction}

Quick Service Restaurants (QSR)/ American Food Restaurants (AFR)/ Limited Food Restaurants (LSR) are uniquely designed restaurants accounting for a central and significant part of the Indian Food Service Industry. These restaurants are premeditated to satisfy the uniquely adventurous tastes of millennials and they offer both fast food Indianite cuisines and also minimal table services in order to cater to the varying requirements of the new age youth belonging to the age group of 15-35 and working professionals who generally don't mind trying out new dishes and who are basically experimental in nature. These restaurants often operate as a part of the chain restaurants or they operate as franchisees. Despite being comparatively nascent, they are highly promising and emerging offering a lot of room for expanding their potential operations and 
thereby encouraging the overall growth of the service sector.

Indian Quick Service Restaurant Segment is dominated by foreign, highly reputed and well established brands who have been the major market players since their inception. This segment has been under scan from the very time it was introduced in India as there are several global drivers accounting for its growth which has made it escalate and move on an upswing, namely; increasing demand by households for convenient foods on account of urbanization where in families are time-bound and are left with very little time to undertake cooking thereby increasing their dependence on these foods. Also varying and constantly changing tastes and preferences of consumers with greater disposable incomes, having access to a large number of options from highly competitive brands, availability of cheap labour, designing products and foods customized to different customers requirements and needs with many of them being increasingly health conscious opting for well labeled and nutritional information containing foods has enabled QSR's to develop a firm foothold within the service sector.

\section{Objectives of the study}

The study aims to draw attention towards lesser known aspects such as consumers mode of purchase and relevance of American foods and their monthly expenditure and per visit expenditure on American foods.

\section{Materials and Methods}

Both primary and secondary data was collected for fulfilling the objectives of the study out of which, for primary data collection, 90 consumers of American style foods and seven American Food Restaurants (AFR's) were interviewed using a structured and pre-tested schedule to know the estimate of expenses on American foods by consumers in Bengaluru City. The collected data was tabulated and analyzed using simple percentage analysis.

\section{Results and Discussion}

The outcomes of the study have been highlighted below under suitable headings with detailed explanations.

\section{Consumers' mode of purchase of American foods}

The consumers have a choice to purchase American foods from AFR's via different modes. The preference for a particular mode of purchase of American food is presented in Table 1. It can be observed from the Table that nearly three fourths of the consumers (70\%) purchased American food at the restaurant itself followed by 28.88 per cent of the consumers who purchased American foods over telephone. Further, only 8.88 per cent of the consumers purchased American foods online.

\section{Consumers monthly expenditure on American foods}

The consumption expenditure towards American foods by the sample consumers was analyzed and the results are presented in Table 2.It could be observed from the Table that 25.56 per cent of the consumers spent Rs. 2500-3000 on American foods per month whereas, 23.33 per cent of the consumers expenditure on American foods ranged between Rs. 500-1000. About 22.22 per cent of the consumers spent Rs. 1500-2000 per month on eating outside and 11.11 per cent of the consumers spent Rs. 3500-5000 per month on American foods. Further only 8.89 per cent of the consumers spent Rs. 100-500 on American foods while only 5.56 per cent of 
the consumers spent Rs. 1001-1500. Only a negligible portion of the consumers $(3.33 \%)$ spent between Rs. 2000-3500 per month on eating American foods.

\section{Consumers' expenditure on eating American foods (per visit)}

The consumers' expenditure on eating American foods (per visit) is presented in Table 3. A little more than two thirds of the consumers (67.78\%) spent Rs. 100-500on eating American foods (per visit) followed by nearly one fourths of the consumers $(24.44 \%)$ spending Rs. 1000-2000 on eating out. Further, only 7.78 of the consumers spent Rs. 500-1000 on eating American foods. This is also presented in Fig.1.

\section{Relevance of American foods}

Table 4 presents the relevance of American foods. It was found that 37.77 per cent of the consumers opined that they consumed American foods to satisfy cravings followed by one third of the consumers $(33.33 \%)$ who consumed American foods as they considered it to be a substantial snack. About one fourth of the consumers $(24.44 \%)$ believed it to be a suitable meal substitute/ replacement. It is interesting to note that 12.22 per cent of the consumers consumed American foods for evading boredom in their lives. This is also presented in Fig.2.

The results indicated in the previous section have been discussed with their reasons below:

\section{Consumers' mode of purchase of American food}

The consumers have a choice to purchase American foods from AFR's via different modes. Nearly three fourths of the consumers (70\%) purchased American food at the restaurant itself followed by 28.88 per cent of the consumers who purchased American foods over telephone and had the foods home delivered. Further, only 8.88 per cent of the consumers purchased American foods online (Table 1).

Bengaluru having a multi-national population base comprises of people whose food habits are influenced by the emphatic presence of foreigners. The traditional cuisine is being given an Indian or Iranian or Lebanese twist to create variety or to introduce modernity. American food is primarily looked upon as a means of meeting the needs of expatriates. International cuisine is freely accessible and so most consumers prefer purchasing food at the restaurant itself as it gives them the choice to explore a variety of menu options which is not possible over telephone/ online.

Also, most consumers want to leisurely enjoy the meal given the ambience, air conditioning and other attractive attributes of the restaurant. For consumers who prefer the delivery of foods at their doorstep, due to their hectic working hours and fast-paced lifestyles, the detailed evening meals have gathered importance in social and family respects and so they order the foods over telephone or online. Shoyemi (2014) reported similar results in his study.

\section{Consumers' monthly expenditure on American foods}

Significant findings have revealed that 25.56 per cent of the consumers spent Rs. 2500-3000 on American foods per month whereas, 23.33 per cent of the consumers' expenditure on American foods ranged between Rs.500-1000. About 22.22 per cent of the consumers spent Rs. 1500-2000 per month on eating outside and 11.11 per cent of the consumers spent Rs.3500-5000 per month on American foods. 
Table.1 Consumers mode of purchase of American food ( $\mathrm{n}=90)$

\begin{tabular}{|c|l|c|c|}
\hline $\begin{array}{c}\text { Sl. } \\
\text { No. }\end{array}$ & \multicolumn{1}{|c|}{ Mode of purchase } & \multicolumn{1}{|c|}{$\begin{array}{c}\text { Number of } \\
\text { consumers }\end{array}$} & Percentage \\
\hline 1. & At the restaurant itself & 63 & 70.00 \\
\hline 2. & Over telephone & 26 & 28.88 \\
\hline 3. & Online & 8 & 8.88 \\
\hline
\end{tabular}

Note: Multiple responses were given by the respondent / consumer

Table. 2 Consumers monthly expenditure on American foods $(n=90)$

\begin{tabular}{|c|l|c|c|}
\hline $\begin{array}{c}\text { Sl. } \\
\text { No. }\end{array}$ & \multicolumn{1}{|c|}{ Expenditure } & $\begin{array}{c}\text { Number of } \\
\text { consumers }\end{array}$ & $\begin{array}{c}\text { Percentage to the } \\
\text { total }\end{array}$ \\
\hline 1. & Rs. $100-500$ & 8 & 8.89 \\
\hline 2. & Rs. $501-1000$ & 21 & 23.33 \\
\hline 3. & Rs. $1001-1500$ & 5 & 5.56 \\
\hline 4. & Rs. $1501-2000$ & 20 & 22.22 \\
\hline 5. & Rs. $2001-2500$ & 1 & 1.11 \\
\hline 6. & Rs. $2501-3000$ & 23 & 25.56 \\
\hline 7. & Rs. $3001-3500$ & 2 & 2.22 \\
\hline $\mathbf{8 .}$ & Rs. $3501-5000$ & 10 & 11.11 \\
\hline & Total & $\mathbf{9 0}$ & $\mathbf{1 0 0 . 0 0}$ \\
\hline
\end{tabular}

Table.3 Consumers expenditure on eating American foods (per visit) $(\mathrm{n}=90)$

\begin{tabular}{|c|l|c|c|}
\hline $\begin{array}{c}\text { Sl. } \\
\text { No. }\end{array}$ & \multicolumn{1}{|c|}{ Expenditure } & $\begin{array}{c}\text { Number of } \\
\text { consumers }\end{array}$ & $\begin{array}{c}\text { Percentage to the } \\
\text { total }\end{array}$ \\
\hline 1. & Rs. $100-500$ & 61 & 67.78 \\
\hline 2. & Rs. 501-1000 & 7 & 7.78 \\
\hline 3. & Rs. 1001-2000 & 22 & 24.44 \\
\hline & Total & $\mathbf{9 0}$ & $\mathbf{1 0 0 . 0}$ \\
\hline
\end{tabular}

Table.4 Relevance of American foods $(\mathrm{n}=90)$

\begin{tabular}{|c|l|c|c|}
\hline $\begin{array}{c}\text { Sl. } \\
\text { No. }\end{array}$ & \multicolumn{1}{|c|}{ Relevance } & $\begin{array}{c}\text { Number of } \\
\text { consumers }\end{array}$ & Percentage \\
\hline 1. & Satisfying cravings & 34 & 37.77 \\
\hline 2. & Substantial snack & 30 & 33.33 \\
\hline 3. & Meal substitute / replacement & 22 & 24.44 \\
\hline 4. & Evading boredom & 11 & 12.22 \\
\hline
\end{tabular}

Note: Multiple responses were given by the respondent / consumer 
Fig.1 Consumers expenditure on eating American foods (per visit)

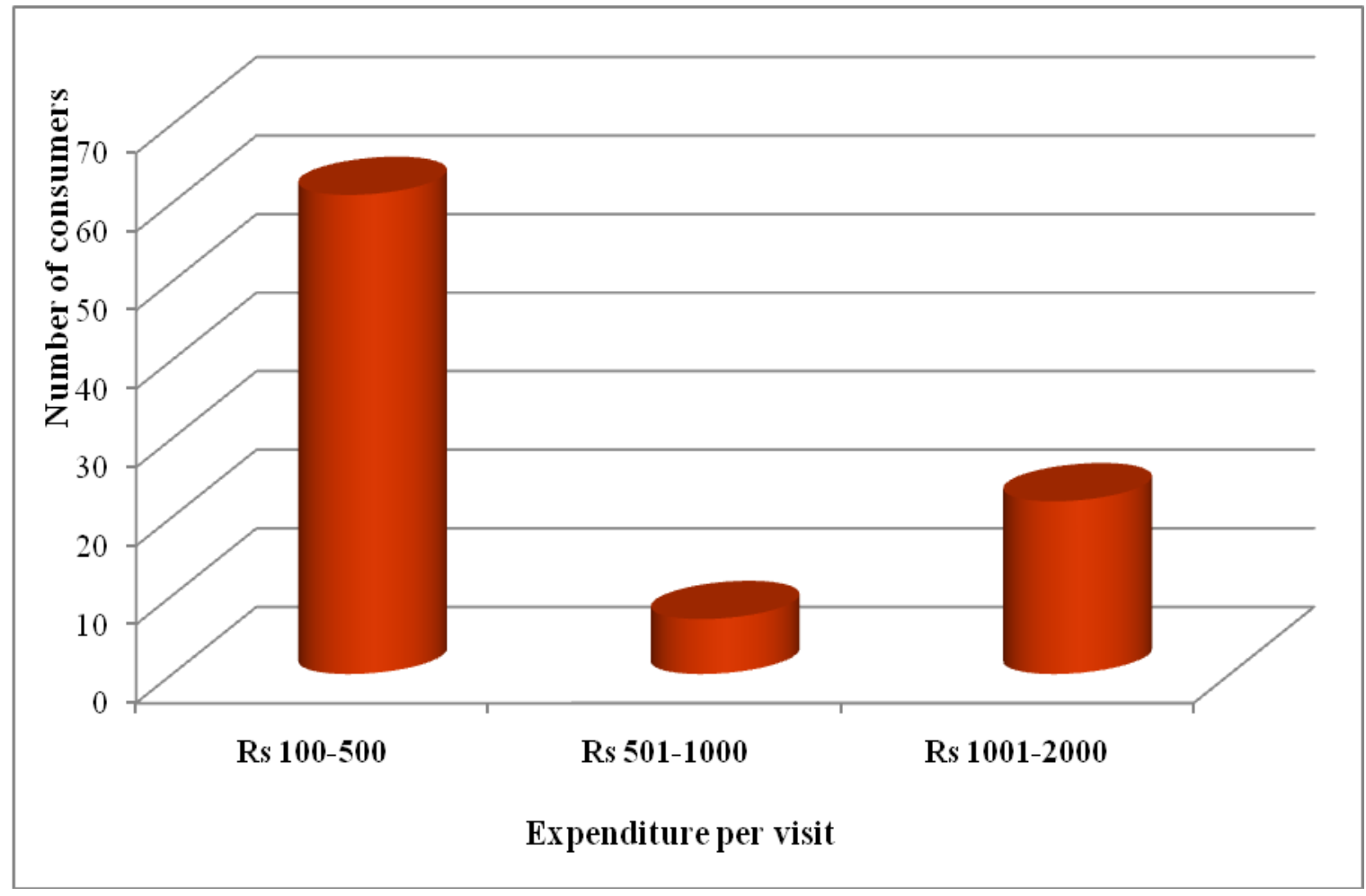

Fig.2 Relevance of American foods

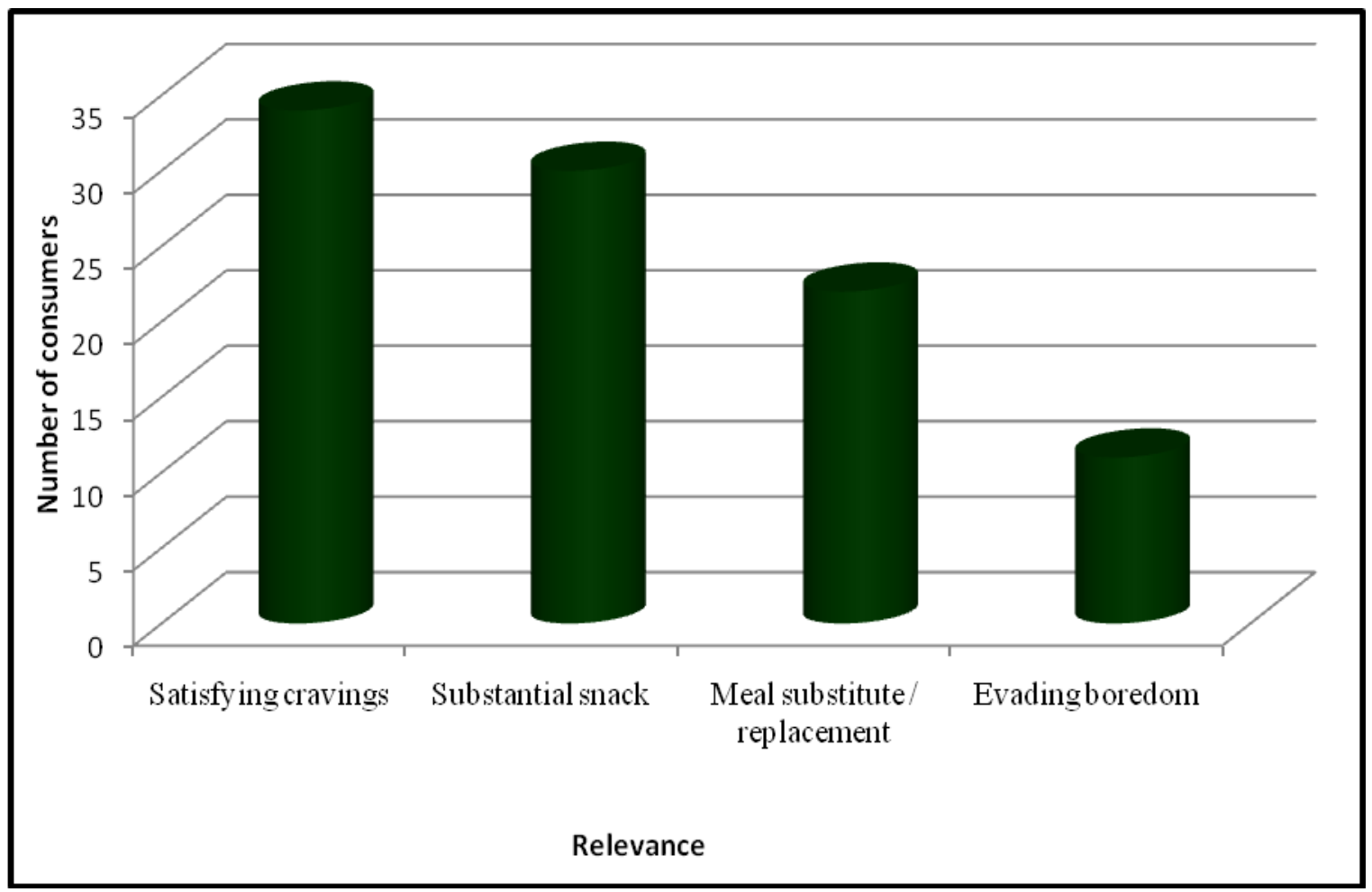


Further only 8.89 per cent of the consumers spent Rs. 100-500 on American foods while only 5.56 per cent of the consumers spent Rs. 1001-1500. Only a negligible portion of the consumers $(3.33 \%)$ spent between Rs. 20003500 per month on eating American foods (Table 2). Hence, it is clearly evident that the sample consumers spent considerable amount of their income for eating outside due to their convenient lifestyle as it saves their time.

The rising income levels in the population is a very interesting phenomena because of two reasons, one being the fact that 55 percent of the population is under the 25 years of age and also, the altered structure of families, especially the nuclear families having more than one earning member and those that are residing in cities. What this leads to is an increase in spending, but an increase in spending with a changed consumer behavior and so subsequently a change in the eatingout habits of the population is also seen. It is seen that more and more people eat out these days for a multitude of reasons, ranging from the lack of option for a home cooked meal to desiring a comforting and soothing experience from a tough day at work, yearning privacy in order to spend time with associates/ family members. With their increasing number of visits or with increasing frequency of visits, consumers' expenditure on these American foods also increases. Zafar et al., (2002), Prabhavathi et al., (2014) and Srividhya (2014) reported similar results in their studies.

\section{Consumers' expenditure on eating American foods (per visit)}

A little more than two thirds of the consumers $(67.78 \%)$ spent Rs. $100-500$ on eating American foods (per visit) followed by nearly one fourths of the consumers (24.44\%) spending Rs. 1000-2000 on eating out. Further, only 7.78 of the consumers spent Rs. 500-1000 on eating American foods (Table 3 and Fig. 1). Young consumers are spending considerable amount of their income for eating outside due to their convenient lifestyle as it saves their time and it is found that consumers on an average spend Rs.150Rs.500 / meal (Assocham, 2013). Prabhavathi et al., (2014) reported similar results in their study.

\section{Relevance of American foods}

Significant findings revealed that 37.77 per cent of the consumers opined that they consumed American foods to satisfy cravings followed by one third of the consumers (33.33\%) who consumed American foods as they considered it to be a substantial snack followed by one fourth of the consumers who believed it to be a suitable meal substitute/ replacement. A minor per cent of the consumers consumed American foods for evading boredom (Table 4 and Fig. 2).

Consumers eat out from AFR's whenever they have cravings for these kinds of food given their satiety value and appetizing nature. Most consumers patronizing AFR's consider American foods to be very filling especially as a snack while many others consider it to be a suitable replacement for home-made foods.

Nearly three fourths of the consumers (70\%) purchased American foods at the restaurant itself followed by 28.88 per cent of the consumers who purchased American foods over telephone. The consumers who spent Rs. 2500-3000 on American foods per month constituted 25.56 per cent whereas, 23.33 per cent of the consumers expenditure on American foods ranged between Rs. 5001000.A little more than two thirds of the consumers (67.78\%) spent Rs. 100-500 on eating American foods (per visit) followed by nearly one fourths of the consumers $(24.44 \%)$ spending Rs. 1000-2000 on eating out. About 
37.77 per cent of the consumers opined that they consumed American foods to satisfy cravings followed by one third of the consumers (33.33\%) who consumed American foods as they considered it to be a substantial snack.

\section{Recommendations and Suggestions}

AFR's can also offer special dishes and change the specials regularly to satisfy adventurous diners who would like to try out new flavours as preferred by the consumers.

\section{References}

http://www.assocham.org/publications.php Prabhavathi, Y., Kishore, N. T. K. and Kumar M. R., 2014, Consumer preference and spending pattern in Indian fast food industry. International Journal of Scientific and Research Publications, 4 (2): $1-5$

Shoyemi, A. O., 2014, Consumer's perception of International Quick Service Restaurants in Nigeria: A case study of Kentucky Fried Chicken (KFC). MBA (International) Project Report (Unpublished), Dublin Business School., Nigeria.

Srividhya, N., 2014, Eating out habit of individuals - An analytical study (With special reference to Puducherry city). International Journal of Business and Management Invention, 3 (6): 38-44

Zafar, M. I., Abbasi, S., Chaudhry, A. and Riaz, A., 2002, Consumer behavior towards fast food. Pakistan Journal of Food Science, 12(3): 71-75

\section{How to cite this article:}

Pooja S. Bhat, T.N. Venkata Reddy and Mandanna, P.K. 2018. An Estimation of the Consumers Expenditure on the Consumption of American Foods. Int.J.Curr.Microbiol.App.Sci. 7(02): 1626-1632. doi: https://doi.org/10.20546/ijcmas.2018.702.196 